\title{
DESIGN DE EMBALAGEM: PROPOSTA DE EMBALAGEM PARA POLPA DE JUÇARA VENDIDA EM PONTOS POPULARES
}

Gisele Reis Correa Saraiva, Mestra

Universidade Federal do Maranhão - UFMA

gisarco41@gmail.com

Arthur José Silva Marques

Universidade Federal do Maranhão - UFMA

arthurgarre@gmail.com
Camila Monteiro Matias

Universidade Federal do Maranhão - UFMA

camilamonteirodzn@gmail.com

Marcos Anderson Machado Silva

Universidade Federal do Maranhão - UFMA

Marcosanderson.ms@hotmail.com

Thissiany Louisy dos Santos Correia

Universidade Federal do Maranhão - UFMA

Thissy_louise@hotmail.com

Resumo: O presente trabalho intitulado "Design de embalagem: proposta de embalagem para polpa de juçara vendida em pontos populares" referese a uma pesquisa teórico e prática, realizada pelos alunos da disciplina Embalagem, do curso de Design, da Universidade Federal do Maranhão, que tem por objetivo criar uma embalagem secundária para a polpa de juçara vendida em pontos populares da llha de São Luís. Para fundamentação teórica traz-se considerações sobre embalagem com ênfase nas suas funções e classificação e sobre a juçara, fruta conhecida nos outros estados brasileiros como açaí. Todo processo foi orientado pela metodologia de Mestriner (2005), resultando em quatro propostas executadas com materiais de baixo custo, tecnologia simples, podendo ser produzida pelo próprio vendedor da polpa de juçara.

Palavras-chave: Design, embalagem, juçara.

Abstract: This paper named "Packing design: packing proposal for juçara's pulp sold at popular places", refers to a theoretical and practice research, performed by students of the discipline Packaging, of Design Course, from Universidade Federal do Maranhão which aims create a secondary packing for juçara's pulp sold on popular places of Saint Louis Island. For theoretical foundation considerations about packaging are made with emphasis on its functions and characteristc and about the juçara, fruit known in other states as açaí. The whole process was guided by Mestriner methodology (2002), resulting in four proposals implemented with low-cost materials, simple technology, and it can be produced by the vendor himself of juçara's pulp.

Palavras-chave: design, packing, juçara. 


\section{INTRODUÇÃO}

O Maranhão é um estado brasileiro que embora geograficamente localizado na região nordeste, possui características fortíssimas da região norte, por se encontrar na área de transição entre essas duas regiões. Esse fato singular contribui para que o Estado possua um variado e rico ecossistema, que vai da Floresta Amazônica e litoral a cerrados e pântanos.

Inserido nesse potencial territorial, está a juçara, palmeira conhecida nos demais estados brasileiros como açaí e de cujo fruto se extrai um líquido de cor roxa. 0 Maranhão é o segundo estado responsável pela maior produção de juçara no Brasil, com mais de 10.000 toneladas/ano, perdendo apenas para o Pará que produz mais de 93.000 toneladas/ano (INSTITUTO BRASILEIRO DE GEOGRAFIA E ESTATÍSTICA, 2009).

A juçara é um fruto típico da região amazônica e bastante apreciado pela população maranhense. É comum passear por São Luís, capital do Maranhão, em qualquer época do ano e encontrar pontos de venda da polpa da juçara distribuídos pela cidade. De acordo com Oliveira (2003), só nas sete principais feiras de São Luís, funcionam 27 pontos de venda e as famílias que ali trabalham tem a juçara como um esteio para manutenção das suas famílias. Há famílias que trabalham a mais de 35 anos com a venda da polpa.

A polpa é vendida em saco plástico de 1 litro e é transportada pelo consumidor em sacolas plásticas. Muitas vezes essas sacolas se rompem durante o transporte, causando o desperdício do líquido e prejuízo ao consumidor.

Diante do exposto, o presente trabalho tem por objetivo projetar uma embalagem de transporte para a polpa da juçara, que garanta de forma segura o deslocamento pelo consumidor, do ponto de venda ao momento do consumo.

\section{EMBALAGEM}

Etimologicamente a palavra embalagem está associada ao verbo embalar que significa ato de proteger e carregar, dessa forma contemplando as funções primárias da embalagem: proteger e transportar (NEGRÃO; CAMARGO, 2008).

Atualmente o seu o uso não está restrita apenas a essas funções, além de guardar e conservar, armazenar e transportar, também informa, identifica e promove, ou seja, contém, protege e comunica. A contenção está relacionada ao ato de acondicionar o produto, a proteção refere-se à preservação da integridade física e química do produto e a comunicação, permite levar as informações.

Nesse sentido, a Associação Brasileira de Embalagem - ABRE (2016) conceitua embalagem como um recipiente ou envoltura que armazena produtos temporariamente, individualmente ou agrupando unidades, tendo como principal função protegê-lo e estender o seu prazo de vida (shelf life), viabilizando sua distribuição, identificação e consumo.

Para Mestriner (2002), conter, proteger, identificar, expor, comunicar e vender o produto são tarefas que a embalagem moderna precisa desempenhar com eficiência para fazer o produto existir em um cenário cada vez mais competitivo. Mas para que a mesma contemple suas funções, precisa de uma estrutura física para cada etapa de sua existência, sendo assim passou a ser classificada como primária, secundária e terciária. 
A embalagem primária é a embalagem de venda, aquela que está em contato direto com o produto e consequentemente com o consumidor final, no ponto de compra. A embalagem secundária ou embalagem agrupada tem por objetivo agrupar um determinado número de unidades de venda, sendo que as características do produto não serão alteradas se removido, e pode exercer também a função de proteger a embalagem primária, em seu interior, evitando choques e vibrações excessivas. A embalagem terciária visa proteger a mercadoria durante as fases do transporte.

Após o uso a embalagem também adquire funções, ela pode ser descartada, ou retornar ao processo de fabricação do produto para reenvasamento, e ainda reutilizada, sendo reaproveitada pelo consumidor para o acondicionamento de outros produtos. O descarte é um grande problema que envolve a embalagem, pois muitos materiais utilizados na sua fabricação não são biodegradáveis permanecendo no meio ambiente por muito tempo e gerando lixo, causando impactos ambientais, podendo ser mais ou menos significativos, de curta ou longa duração e ainda locais, regionais ou globais.

Embora a indústria de embalagem venha trabalhando intensamente em algumas frentes, como adoção de técnicas de produção limpa, redução do consumo de recursos naturais, aprimoramento dos materiais, redução na fonte da espessura / volume, reutilização, reciclagem dos materiais, as ações ainda são poucas diante da quantidade que é descartada diariamente.

A embalagem, assim como qualquer outro produto, causa impactos ambientais ao serem produzidos e consumidos, em todas as suas etapas de vida: aquisição de matéria-prima, fabricação distribuição, uso e descarte final. Por isso deve ser pensada para ser um produto eco- eficiente, ou seja, garantir a satisfação pelo serviço oferecido e reduzir o impacto ambiental (poluição e consumo), como afirma Manzini e Vezoli (2008).

O design como atividade envolvida nesse processo tem a responsabilidade de pensar que além da embalagem chamar a atenção do consumidor, transmitir informação, ressaltar os atributos e agregar valor, precisa "promover a capacidade do sistema produtivo de responder à procura social de bem-estar, utilizando uma quantidade de recursos ambientais, drasticamente inferior aos números atualmente praticados" (MANZINE; VEZOLI, 2008, p.23).

Sendo assim, o design está inserido no âmbito da cultura de uma sociedade, influenciando a construção de valores, práticas e hábitos das pessoas, tornando o designer, sujeito e objeto da dinâmica cultural, atribuindo dessa forma à atividade, o caráter sustentável.

\section{JUÇARA, O AÇAÍ DO MARANHÃO}

Euterpe Oleracea Mart é o nome científico de uma espécie de palmeira nativa da Região Amazônica, o açaizeiro, que produz o fruto conhecido popularmente em todo território Nacional como açaí. Esta palmeira, dentro do território brasileiro distribui-se nos Estados do Pará, Amapá, Maranhão e Amazonas, predominante em áreas úmidas, em vários tipos de solo, desde terra firme a várzeas com inundações periódicas. (OLIVEIRA, 2003)

Entre esses quatro Estados, o Maranhão é o único que possui uma denominação diferente, é conhecida popularmente como juçara, mesmo nome da 
espécie encontrada na Mata Atlântica, no entanto, entre as duas palmeiras é comum apenas o nome popular, pois a juçara existente na Mata Atlântica pertence a outra espécie, a Euterpe Edulis Mart. (CORREA, 2010)

\section{EMBALAGEM: O PROJETO}

Este trabalho foi desenvolvido durante a disciplina Embalagem, no curso de Design da Universidade Federal do Maranhão. Foi pedido aos alunos que projetassem uma embalagem secundária para transportar a embalagem primária da polpa da juçara.

Para desenvolvimento das propostas foi utilizado como referência a metodologia de Mestriner (2005) que aponta 5 fases para o design de embalagem: briefing - informações chave; estudo de campo - condições reais; estratégia de design - síntese objetiva das etapas anteriores; desenho - detalhamento do projeto e, implantação do projeto - definição da tecnologia empregada para produção.

\subsection{Problema}

A polpa da juçara vendida nos estabelecimentos populares é acondicionada em saco plástico transparente, de 1 litro (embalagem primária) (figura 1) e transportado pelo consumidor final em sacolas plásticas (embalagem secundária). Embora o saco da embalagem primária seja resistente, a sacola de transporte é muito frágil e dependendo da forma como é transportado pode furar ou romper com impactos, ocasionado o desperdício do líquido. Também não há, em nem uma das embalagens, algo que identifique o produto, ou seja, procedência, identidade visual, preparo, conservação, validade e outras informações técnicas.

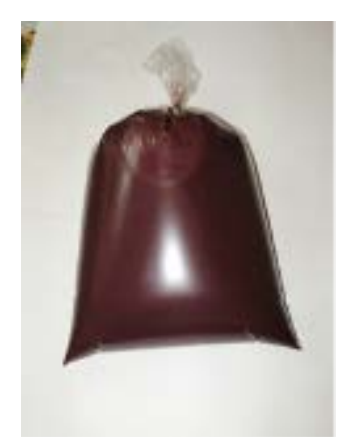

Figura 1 - polpa da juçara na embalagem de venda.

Fonte: Elaborado pelo autor, com base na pesquisa realizada.

\subsection{Objetivo}

Projetar uma embalagem secundária para a polpa de juçara vendida em pontos populares da Ilha de São Luís.

\subsection{Requisitos}

- Contemplar as funções da embalagem;

- Criar a identidade visual;

- Identificar os elementos da linguagem visual;

- Conter as informações necessárias pelas normas e legislação vigente;

- Ser reutilizável e/ou reciclável; 
- Utilizar tecnologia simples, com custo baixo e que possa ser fabricada pelo próprio vendedor.

\subsection{Geração de alternativas}

Esta etapa é fundamental para o desenvolvimento de um produto, pois é o momento em que pode se analisar e configurar as reais necessidades do cliente e as possíveis alternativas viáveis para a execução. Portanto, levou-se em consideração as pesquisas feitas com os consumidores e os requisitos propostos, e após várias ideias esboçadas, escolheu-se as quatro alternativas finais.

A seguir é apresentado o desenvolvimento das propostas, mostrando os materiais, a tecnologia, os elementos da linguagem visual e o rótulo com as informações necessárias à categoria de produto para qual a embalagem é destinada.

\subsection{Proposta 01}

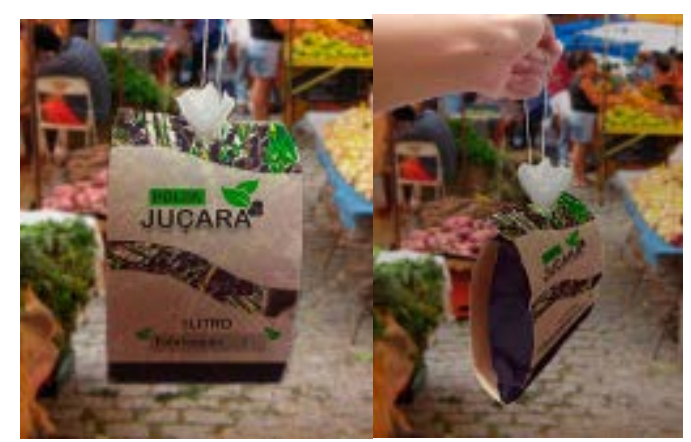

Figura 2 - proposta 01

Fonte: Elaborado pelo autor, com base na pesquisa realizada.

\subsubsection{Materiais}

Para esta proposta utilizou-se como materiais o papelão ondulado duplex (figura 3) e o sisal. O sisal é uma planta utilizada como matéria-prima na produção de fios, sendo considerada a fibra vegetal mais dura que existe.

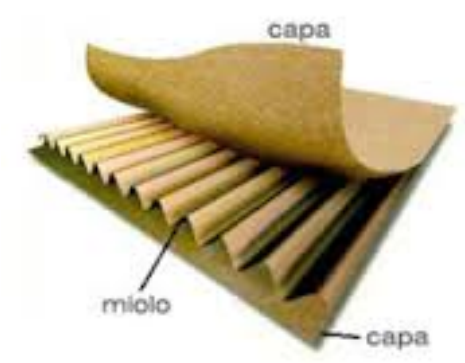

Figura 3 - estrutura papelão ondulado

Fonte:http://etescoembalagens.com.br/blog/papelao-ondulado-caracterizacao-tecnica/

\subsubsection{Tecnologia}

Na confeç̧ão da embalagem, o papelão ondulado é utilizado para o corpo da embalagem, formado por uma peça de medidas $560 \mathrm{~mm} \times 160 \mathrm{~mm}$, com uma dobra ao meio no sentido horizontal e com um corte nas extremidades para encaixar o nó da embalagem primária da juçara (figura 4). O sisal é utilizado para a alça, montada conforme com a figura 5 . 


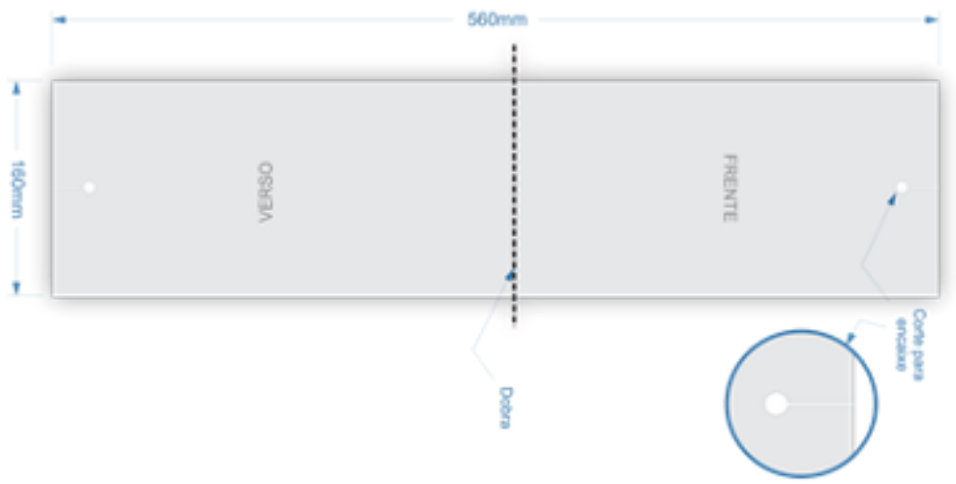

Figura 4 - planificação proposta 01

Fonte: Elaborado pelo autor, com base na pesquisa realizada.

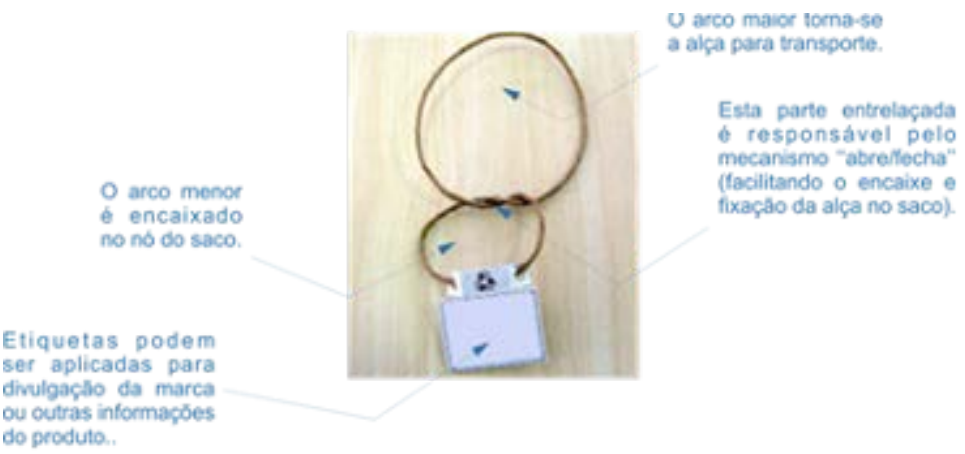

Figura 5 - alça confeccionada em sisal

Fonte: Elaborado pelo autor, com base na pesquisa realizada.

\subsubsection{Elementos da linguagem visual}

A proposta trouxe a cor roxa, forte e vibrante, da juçara para o rótulo e marca do produto, mesclada à cor verde, fazendo referência a natureza, árvores e folhas. Ao fundo como background, está a imagem da juçareira, aproximando o produto final (polpa), do fruto e da árvore, trazendo a experiência do natural e saudável.

A marca é composta pelo um nome e um grafismo representando o fruto da juçareira. A tipografia adotada é sem serifa, de fácil leitura e com terminações arredondadas que trazem fluidez ao layout e o torna mais descontraído.

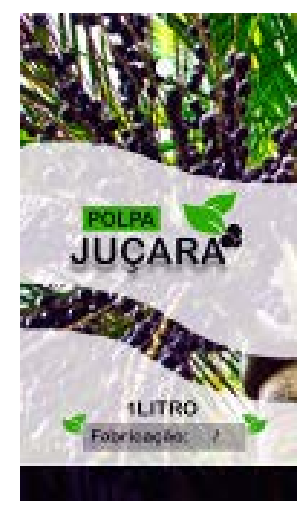

Figura 6 - Layout proposta 01

Fonte: Elaborado pelo autor, com base na pesquisa realizada. 


\subsubsection{Rótulo}

Informações contidas no rótulo: o nome do produto, peso líquido, data de fabricação, origem e informações nutricionais (figura 7).

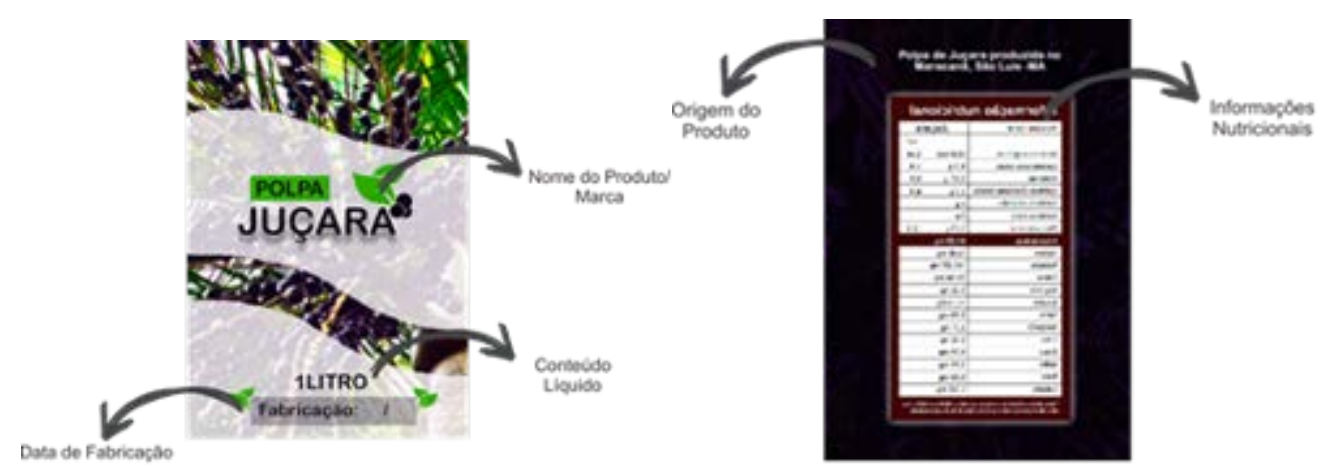

Figura 7 - rótulo proposta 01

Fonte: Elaborado pelo autor, com base na pesquisa realizada

\subsection{Proposta 02}

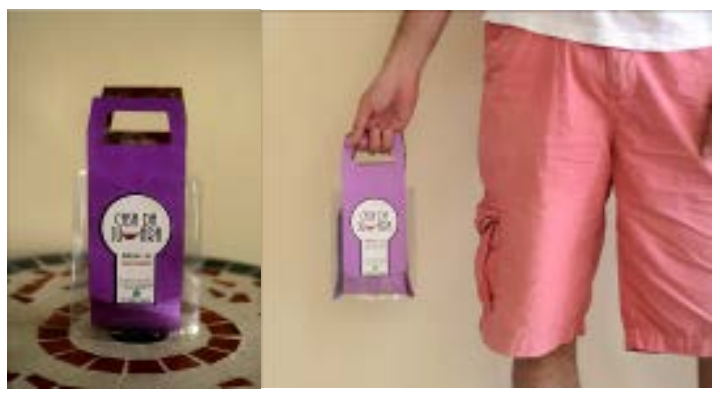

Figura 8 - proposta 02

Fonte: Elaborado pelo autor, com base na pesquisa realizada.

\subsubsection{Materiais}

Nesta proposta utilizou-se como materiais o papel cartão e o pet de garrafas de refrigerante, por ser um material de descarte após o uso e de fácil aquisição.

\subsubsection{Tecnologia}

A garrafa pet é utilizada na embalagem como peça de proteção à embalagem primária. Para fabricação, a garrafa é cortada nas duas extremidades adquirindo a altura de $18 \mathrm{~cm}$. Com o papel cartão é feito a alça que é composta por uma tira de $56 \mathrm{~cm} \times 10 \mathrm{~cm}$, com vincos e uma pega com duas peças de $8 \mathrm{~cm} \times 10 \mathrm{~cm}$. As peças da pega depois de prontas são coladas na extremidade da tira, formando uma única peça (figura 9). A alça além de permitir a pega, envolve a garrafa de pet (figura 10). 


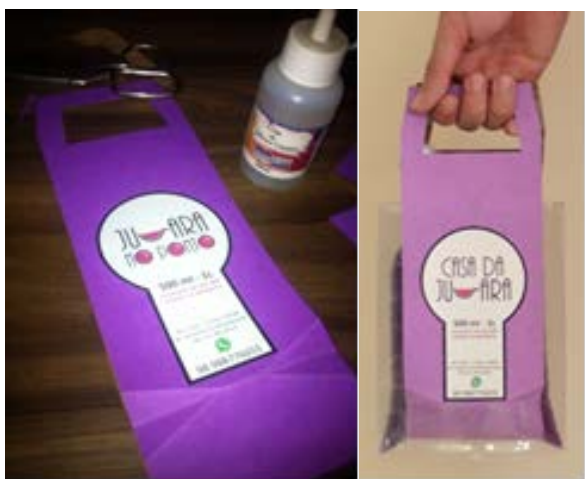

Figura 9 e 10 - alça e embalagem pronta .

Fonte: Elaborado pelo autor, com base na pesquisa realizada.

\subsubsection{Elementos da linguagem visual}

O nome da marca foi executado com a fonte $\operatorname{Ar}$ bonnie, na cor preto, apresentando como detalhe a letra " $\mathrm{C}$ " do nome "juçara", colocado de forma invertida e preenchida com um semi círculo na cor roxo (cor da juçara) para trazer referência ao recipiente onde se bebe a polpa da fruta (figura 11 ).

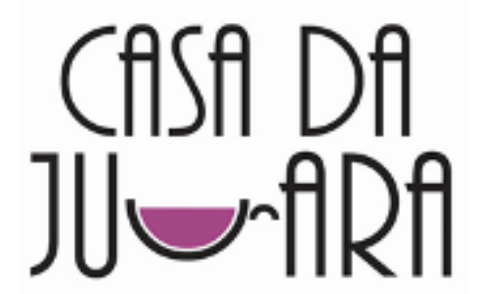

Figura 11 - logotipo proposta 02

Fonte: Elaborado pelo autor, com base na pesquisa realizada

\subsubsection{Rótulo}

Informações contidas no rótulo: o nome do produto, peso líquido, validade, modo de conservação, telefone, origem, informações nutricionais e simbologia técnica dos materiais (figura 12).

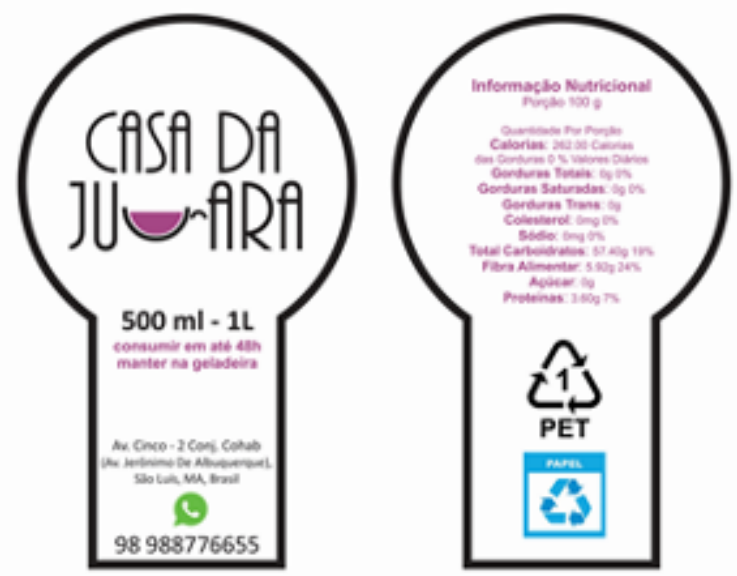

Figura 12 - rótulo proposta 02

Fonte: Elaborado pelo autor, com base na pesquisa realizada 


\subsection{Proposta 03}

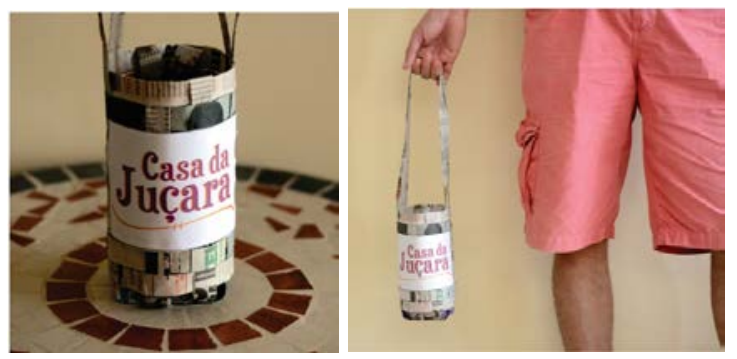

Figura 13 - proposta 03

Fonte: Elaborado pelo autor, com base na pesquisa realizada.

\subsubsection{Materiais}

O jornal foi o material escolhido para esta proposta, por ganhar resistência ao ser dobrado e revestido com cola, além de ser uma matéria prima descartada logo após o uso.

\subsubsection{Tecnologia}

O processo de fabricação da embalagem consiste em cortar uma página do jornal em quatro tiras, dobrar uma tira duas vezes, passar cola em toda sua extremidade e esperar o tempo de secagem. São necessárias 11 (onze) tiras de 54,5 $\mathrm{cm}$ e 02 (duas) tiras de $106 \mathrm{~cm}$. Para confecção da embalagem, são cruzadas e coladas quatro tiras, duas de 54,5 e duas de $106 \mathrm{~cm}$, para originar a base-estrutura (figura 14), em seguida essa base é fixada a uma garrafa PET e depois trançadas com as nove tiras de 54,5 (figura 15e 16).

Figura 14 - tiras cruzadas e coladas formando a base-estrutura Fonte: Elaborado pelo autor, com base na pesquisa realizada.

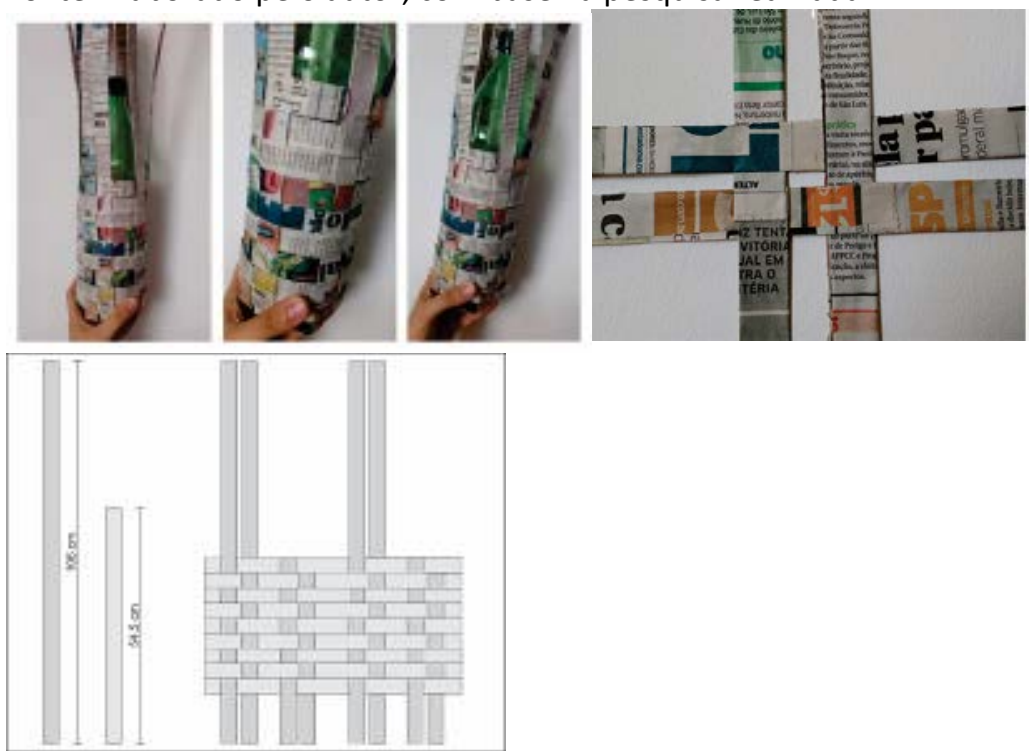

Figura 15 e 16 - tiras trançadas e conformadas no molde. Planificação proposta 03 Fonte: Elaborado pelo autor, com base na pesquisa realizada.

\subsubsection{Elementos da linguagem visual}

Inspirado no design vernacular, a identidade visual traz a tipografia Dualty, remetndo às placas que geralmente são feitas manualmente nesses estabelecimentos. 
O roxo foi utlizado por ser a cor da polpa da juçara e o amarelo por ser uma cor complementar do roxo, evidenciando ainda mais a cor. (figura 17)

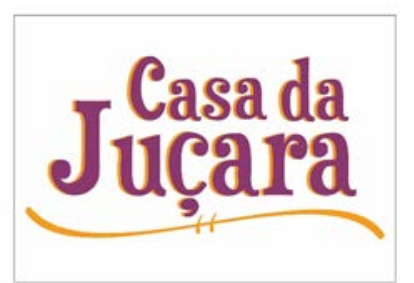

Figura 17 - logotipo proposta 03

Fonte: Elaborado pelo autor, com base na pesquisa realizada

\subsubsection{Rótulo}

Informações contidas no rótulo: o nome do produto, telefone, origem (figura 18).

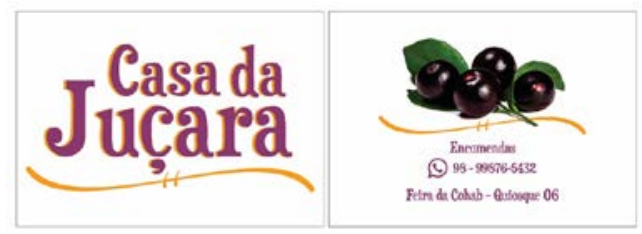

Figura 18 - rótulo proposta 03

Fonte: Elaborado pelo autor, com base na pesquisa realizada

\subsection{Proposta 04}

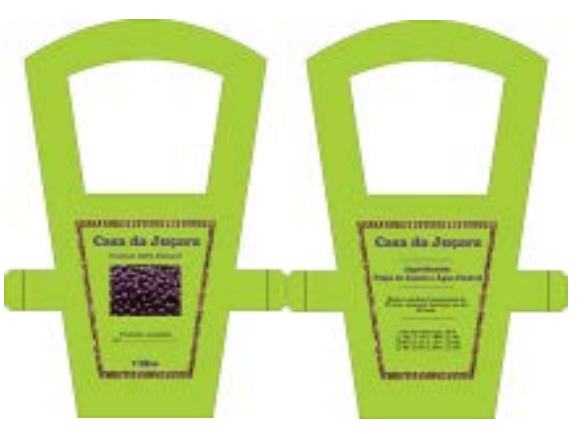

Figura 19 - proposta 04

Fonte: Elaborado pelo autor, com base na pesquisa realizada.

\subsubsection{Materiais}

O TNT $^{1}$ é o material escolhido para essa proposta por ser produto biodegradável e aprovado pelos órgãos que regem e ditam a proteção da ecologia mundial, e se degradam em um tempo muito menor que os plásticos comuns, contribuindo para a redução de resíduos e do lixo urbano, e para a preservação do meio-ambiente.

\footnotetext{
${ }^{1}$ É conhecido como "tecido não tecido" confeccionado em tecido a base de polipropileno e viscose
} 


\subsubsection{Tecnologia}

O TNT compõe toda a peça de medida total de $59,4 \mathrm{~cm} \times 11 \mathrm{~cm}$, conforme detalhado na figura 20. Depois de cortada, a peça é unida pelas tiras laterais com cola especial para tecido, cola quente, ou ainda costurada.

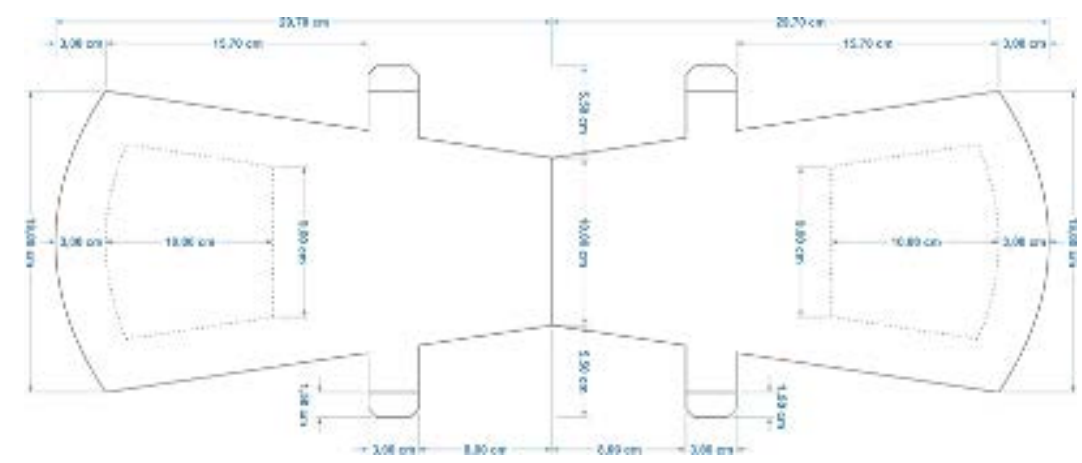

Figura 20 - planificação proposta 04

Fonte: Elaborado pelo autor, com base na pesquisa realizada.

\subsubsection{Elementos da linguagem visual}

As cores escolhidas foram o verde, o roxo e marrom. O verde compõe o corpo da embalagem por representar a folha da palmeira da juçara, em um tom claro para que permita a impressão de outras cores por cima dele, se necessário. 0 roxo e o marrom estão no rótulo. O roxo representa o fruto da juçara, e o marrom representa o caule da palmeira e o cesto de fibra onde os frutos da juçara são recolhidos. (figura 21)

Para a tipografia foram utilizadas as famílias Cooper Black no nome do produto, Berlin Sans FB Demi, para informações mais relevantes e Arial, nas demais informações.
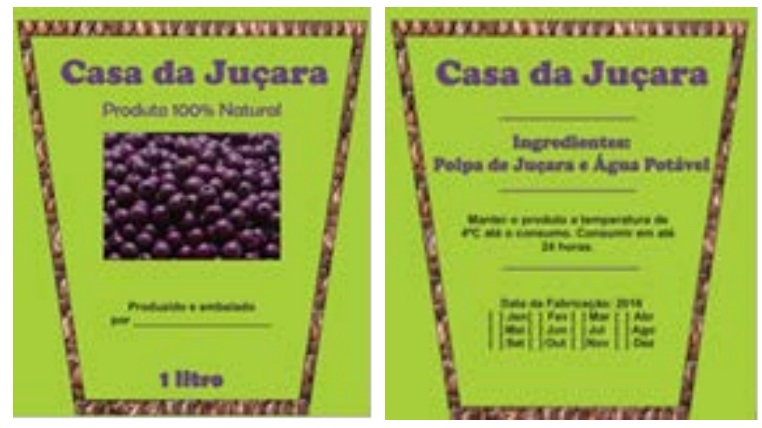

Figura 21 - layout proposta 04

Fonte: Elaborado pelo autor, com base na pesquisa realizada

\section{Rótulo}

Informações contidas no rótulo: o nome do produto, denominação de venda, origem, peso líquido, validade, modo de conservação, ingredientes, instruções sobre preparo (figura 22). O rótulo pode ser impresso em papel comum e fixado à embalagem com cola ou papel adesivo, também tem-se a opção do rótulo ser impresso direto no TNT. 

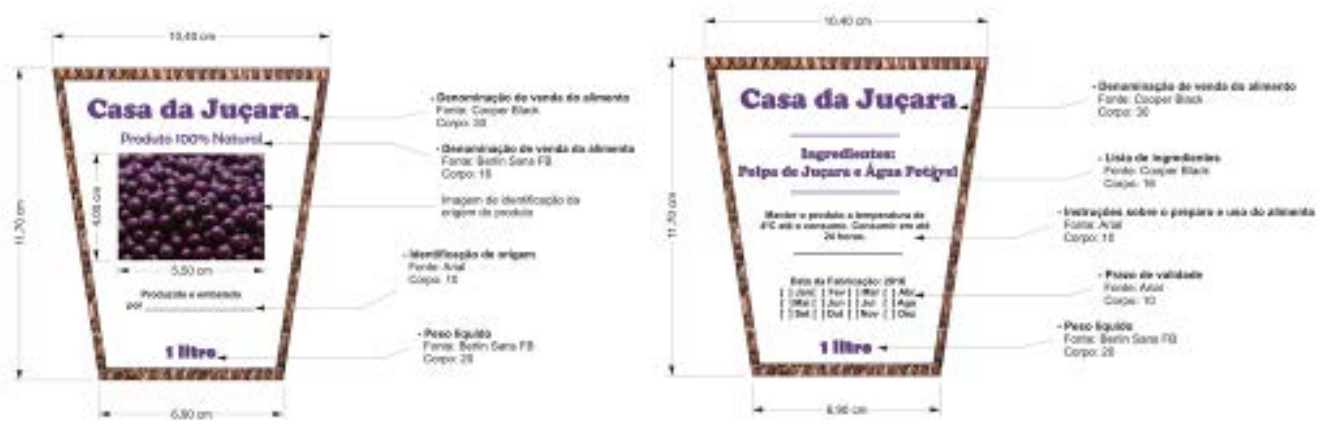

Figura 22 - rótulo proposta 04

Fonte: Elaborado pelo autor, com base na pesquisa realizada

\section{CONCLUSÃO}

O trabalho apresentou o problema encontrado pelo consumidor ao comprar a polpa da juçara e ter que transportá-la até o local de consumo em uma sacola plástica que por sua fragilidade, pode romper durante o transporte. Esse tipo de embalagem é muito utilizado nesses estabelecimentos populares, por apresentar um baixo custo e também pelo fato de não possuir no mercado de São Luís uma embalagem própria e adequada para esse tipo de produto.

Procurou-se resolver esse problema, projetando quatro embalagens, utilizando materiais e tecnologias simples, de fácil acesso e manuseio, e com um custo considerado mínimo, não pensando somente no seu transporte, foco da pesquisa, mas contemplando também as demais funções.

O desenvolvimento de uma embalagem secundária para o transporte da polpa da juçara, de forma que agregue valor a esse mercado típico da cidade de São Luís, onde esse tipo de embalagem ainda é inexistente, mostrou que o design pode propor soluções simples e viáveis, atendendo a necessidade do consumidor, nesse caso, no transporte adequado do produto, e a necessidade do vendedor, com uma embalagem que ele mesmo pode produzir.

\section{REFERÊNCIA}

ASSOCIAÇÃO BRASILEIRA DE EMBALAGEM - ABRE. O que é embalagem. Disponível na internet por http em: www.abre.com.br. Acesso 10 de jan. 2016

CORREA, Gisele Reis. Design e artesanato: um estudo de caso sobre a semente de juçara em São Luís do Maranhão. Dissertação (Mestrado) - Universidade Federal de Pernambuco, Curso de Pós-graduação em Design. Recife, 2010.

INSTITUTO BRASILEIRO DE GEOGRAFIA E ESTASTISTICA - IBGE. Produção extração vegetal. Disponível na internet por http em: www.ibge.gov.br. Acesso em: 12 jun. 2009.

MANZINI, Ezio. VEZZOLI, Carlo. O desenvolvimento de produtos sustentáveis: requisitos ambientais dos produtos sustentáveis. São Paulo: Edusp, 2008.

MESTRINER, Fábio. Design de Embalagem - curso básico. 2 Edição. São Paulo: Pearson Makron Book, 2002. 
MESTRINER, Fábio. Design de Embalagem - curso avançado. 2 Edição. São Paulo:

Pearson Makron Book, 2005.

NEGRÃO, Celso; CAMARGO, Eleida. Design de Embalagem: do marketing à produção. São Paulo: Novatec, 2008.

OLIVEIRA, Laura Rosa Costa. Uso, manejo, conservação e importância sócioeconômica da juçara (Euterpe Oleracea mart.; Palmae) na Ilha de São Luís, Maranhão. 2003. f. 83. Dissertação (Mestrado) - Universidade Estadual do Maranhão, Curso de Pós-graduação em Agroecologia. São Luís, 2003. 